\title{
IMPLEMENTATION OF THE ECONOMIC AND MATHEMATICAL MODEL FOR THE DEVELOPMENT OF THE COMPLEX OF SERVICES FOR PASSENGERS IN THE RAILWAY SECTOR
}

\author{
Ekaterina Razumova', Oksana Ilienko² \\ National Aviation University, Ukraine \\ Viktoriia Ihnatiuk ${ }^{3}$ \\ National Transport University, Ukraine
}

\begin{abstract}
The purpose of the paper is to create an economic and mathematical model for identifying the main areas of service development in the implementation of passenger transportation by railway transport. Methodology. The survey is based on a comparison of data from two sets of respondents surveyed in 20162017, using the same questionnaire. Passengers were asked to fill in questionnaires by themselves. In total, more than 100 passengers were interviewed. The paper also is based on special railway ticket desks reporting forms of 2016-2017. Practical applications. It is proposed the model of serving passengers in the part of the formation of food sets that are offered. Results. It is proved that it is based on the model development of the total value of the passenger's dietary structure and allows them to meet their nutritional needs with minimum cost. Scientifically-based is that the solution to this problem is possible through the formation of a balanced package of services for potential rail passengers of Ukraine, which allows increasing the efficiency of passenger service. To develop the growing passenger traffic, the railways try to increase the capacity of trains by including in the scheme of formation of the most capacious types of cars, which causes a decrease in the quality of passenger service, and sometimes - the population of trains. In order to solve the problems of such a class, the article proposes to establish links between demand, price, and level of purchasing power of transport services consumers, and also it is possible to use methods of correlation analysis and multiple regression. Analysis of results of the study of passenger traffic in some areas of the railway network showed that the replacement of the required type of carriages by others leads to the refusal of a certain number of passengers from the trip. Obviously, the change in the schemes of formation of passenger trains, without taking into account the demand of the population for places by types of cars, can lead to serious losses of profits of passenger railways and an increase in dissatisfaction with the demand of passengers. Taking into account the need of passengers and the requirements of rail transport, the task of choosing rational schemes for the formation of passenger trains can be formulated in the following form. A special place in the service of passengers during the trip is catering. The organization of catering for passengers in trains is one of the most profitable accompanying services and the biological necessity of a person. In the railway transport, a comprehensive system for providing and organizing the feeding of passengers in trains should be developed, based on modern and advanced technologies that provide for certain dietary standards, depending on the duration of the trip and the timetable of trains, and take into account the specifics of the consumption of food for a particular category of passengers.
\end{abstract}

Key words: service, rail sector, passenger, economic and mathematical model.

JEL Classification: M10, R40, R49, R42

\footnotetext{
Corresponding author:

${ }^{1}$ Department of Management Foreign Economic Activity of Enterprises, National Aviation University.

E-mail: krazum@ukr.net

${ }^{2}$ Department of Management Foreign Economic Activity of Enterprises, National Aviation University.

E-mail: oks.ilenko7@gmail.com

${ }^{3}$ Department of Management, National Transport University.

E-mail:nikushek@ukr.net
} 


\section{Introduction}

One of the most important components of ensuring the efficiency of the operation of passenger transport is service. Because of a systematic analysis, it has been established that the service involves not only a general but also an individual approach to passenger service, the performance of individual services and operations that often require additional costs from time, energy, resources and, as a rule, without an additional increase in value serviced facility.

As Aksenov I.M. notes, to ensure a high level of service in the transportation of passengers, comfortable high-speed wagons of the European model, appropriate technical and technological support and infrastructure are needed. Without this, it is impossible to compete with other modes of transport (Shchelkunov, 2011). Passenger transportation service is considered not as an activity of complementing the consumer value of the main service - transportation, but as a system of security that allows improving the conditions for passenger transportation by rail, increasing its competitiveness in the transport market.

A wide range of tasks of transport service requires constant scientific and engineering calculations, improvement of existing and development of new methods, systems, technologies, and techniques for the implementation of passenger transportation. This will move passenger transportation to a higher level of development compared with competitors and reduce the cost of maintenance services.

\section{Survey methodology}

The survey is based on a comparison of data from the two sets of respondents surveyed in 2016-2017, using the same questionnaire. Passengers were asked to fill in questionnaires by themselves. In total, more than 100 passengers were interviewed. The paper also is based on special railway ticket desks reporting forms of 2016-2017. The specifics of transport services reside in a set of different types of service: transport, meals, accommodation, excursions, etc. Formation and production of goods for the transport market require a systematic and regular study of the needs, wishes and demands of the population in passenger transportation. In the servicing, the beginning of working with a passenger on a railway transport should be considered not the moment of purchase of a ticket, and the moment of appearance of a potential passenger need to travel. Study of the need for transport services is the beginning of work with the population (Aksonov, 2012). This requires conducting appropriate research and development in the field of studying and defining the characteristics of such basic concepts as the need, desire, and demand of the population for transportation in the present and in the future.
The purpose of the article is the development of an economic and mathematical model for identifying the main areas of service development in the implementation of passenger transportation by railway transport.

\section{Passenger transportation and its service maintenance}

When planning passenger transportation and their service maintenance, it is necessary, first, to take into account not only the demand and the frequency of travel, but also the biological needs of the population in food, water, light, clean air, temperature mode in train cars, mobility and a number of other factors. In rail transport, unlike in the car and air transportation, a number of these needs of passengers remain without much attention.

For all flights, for example, apart from of the duration of the flight, passengers are offered refrigeration drinks. Most airlines follow the following scheme: when flying with a running time of 2-2.5 hours cold appetizers are offered, from 2.5 to 6 hours - hot dishes and for more than 6 hours -2 hot dishes, and for long-haul flights (more than 12 hours) - two hot dishes and cold snacks or steak. Recently, "special diet" is practiced depending on the state of health, habits or nationality of passengers. At the high level, the internal environmental parameters on board aircraft are also supported.

Sanitary and hygienic needs of passengers hold the unique position in consumer services. Children and adult passengers with different psycho-physiological features and biological needs experience great inconveniences when traveling in electric trains over time for more than one hour, as well as in long-haul trains when toilets are closed when traveling in ecologically sanitary zones and at long-haul parking.

Recently, information need shave grown for the population. These are, first, periodicals, Internet, e-mail, radio, satellite and cable television, mobile telephone communications, etc. When going on a long-haul trip, the passenger receives, at best, individual periodicals and radio services. He is isolated from his work, family, and the outside world, he experiences discomfort, and the trip becomes unbearably tedious. The share of passengers who wish to buy periodicals, information services and services of various types of communication is more than $60 \%$.

A key aspect of the needs of passengers is personal safety. This is due not only to the technical operation of the rolling stock, but also to the criminal status, drug addiction, and other factors. Passengers who travel by train in the evening and night for long distances, as well as passengers who are involved in their work with business, feel the need for security and protection.

The needs of passengers in the main service transportation, and in additional services are the basis of the development of marketing programs for transport 
services of the population, which should be developed by passenger house holdings at least twice a year, along with the introduction of a new schedule of trains. No less important is the issue of updating the car park for the future. On the basis of requirements for new types of cars, their internal facility and equipment must be human desires and needs, which in recent decades have changed significantly (Kyrylenko, 2014).

When creating new rail services, passenger railways should be able to satisfy the needs of passengers in transport services to the maximum, considering their needs and financial capabilities. Such an approach to the consumer service will allow, in market conditions, not only to retain existing ones but also to attract new passengers.

\section{Transportation fare}

One of the specific features of the organization of passenger transportation is the lack of a solid base of initial data for their planning. The minimum price for the main service - transportation - must cover the cost of rail transport for passengers and the training of trains on the trip, and the price of additional services - to cover the costs of their production, transportation, salaries of staff, premises rent, lighting, heating, advertising, etc. The pricing system in market conditions begins with an analysis of the needs and level of incomes of the segment of the passenger market, which determines the dynamics of its mobility.

There is no universal model for determination of population mobility (Novak, 2006). The connection between the size of the traffic flow, the population of the correspondent points, and the distance between them, according to the authors, can be determined by a "gravitational model". As Razumova K.M. notes (Razumova, 2014), it can be based on the assertion that there is a transport "attraction" between two large settlements, directly proportional to the product of the population of these points and inversely proportional to the distance between them (formula 1):

$$
\Pi_{i j}=\gamma_{i j} \frac{P_{i} \cdot P_{j}}{Д_{i j}^{\beta}},
$$

where: $\Pi_{i j}$ - the flow from the path $i$ to the destination $j ; P_{i}, P_{j}$ - population, respectively, in points $i$ and $j ; Д_{i j}^{\beta}-$ the distance between settlements; $\gamma_{i j}$ - coefficient of proportionality; $\beta$-constant value.

The frequency of passenger travelling depends on many factors, and the main of them is the level of purchasing power of the transport service, which are (Razumova, 2014):

$$
y_{\Pi C}^{t}=\frac{E_{3 \Pi}(t)-E_{\Pi K}(t)}{C_{6}(t)},
$$

where:

$\boldsymbol{y}_{\Pi C}^{t}-$ the level of purchasing power of the transport service at time $\mathrm{t} ; E_{3 I}(t)$ - average monthly salary of the passenger traffic segment in the region for the period of time $t ; E_{\Pi K}(t)$ - consumer basket at time $t$; $C_{6}(t)$ - fare.

The probability of the demand for a trip in a given type of car at time $t$ can be determined by formula 3 :

$$
P(t)=\frac{n_{\phi} Y_{\Pi C}^{t}}{\Pi_{i j}},
$$

where: $n_{\phi}\left(y_{\Pi C}^{t}\right)$ - the actual number of passengers who made a trip to the specified types of car at an appropriate level of purchasing power $\boldsymbol{y}_{\Pi C}^{\prime}$ at time $t$.

In order to identify the connections between demand, price, and purchasing power of transport users, in our opinion, it is expedient to apply methods of correlation analysis and multiple regression.

With linear dependence and available statistical data, a sufficiently reliable dependence of demand for services on their prices can be obtained by using the linear equation of pair regression, as shown in formula 4 :

$$
U_{c i}^{n}=b_{0}+b_{1} \cdot x
$$

where: $x$ - the factor on which predictive value depends (in this case, the price of the service);

$b_{0}, b_{1}$ - unknown coefficients determined by the method of least squares.

Equation 1 will best approximate statistical data if the sum of squares of deviations of empirical values from the values calculated by equation 4 will be minimal (formula 5):

$$
S=\sum_{i=1}^{n}\left(U_{c i}^{\ni}-U_{c i}^{I I}\right)^{2}=\sum_{i=1}^{n}\left(U_{c i}^{\ni}-b_{0}-b_{1} \cdot x_{1}^{2}\right)=\min ,
$$

where: $U_{c i}^{\ni}$ - the statistical value of the value of passenger demand for services that was observed at time t;

$U_{c i}^{I I}$ - forecast term of the value of passenger demand for services, calculated by the regression equation; $\mathrm{n}-$ the number of observations - sales of services.

The minimum condition for $S\left(b_{0}, b_{1}\right)$ is the following equations:

$$
\begin{aligned}
& \frac{d S}{d b_{0}}=0 ; \frac{d S}{d b_{1}}=0 ; \\
& \text { or }\left\{\begin{array}{l}
\sum_{i=1}^{n} U_{c i}^{\ni}-\sum_{i=1}^{n}\left(b_{0}+b_{1} \cdot x_{1}\right)=0 \\
\sum_{i=1}^{n} U_{c i}^{\ni} \cdot x_{i}-\sum_{i=1}^{n}\left(b_{0}-b_{1} \cdot x_{1}\right) \cdot x_{i}=0 .
\end{array}\right.
\end{aligned}
$$

Calculating this system of equations with respect to $b_{0}$ and $b_{1}$, we obtain (Razumova, 2014):

$$
\begin{aligned}
& b_{0}=\frac{\sum_{i=1}^{n} U_{c i}^{\ni} \cdot \sum_{i=1}^{n} x_{1}^{2}-\sum_{i=1}^{n} x_{i} \cdot \sum_{i=1}^{n} x_{i} U_{c i}^{\ni}}{n \cdot \sum_{i=1}^{n} x_{i}^{2}-\left(\sum_{i=1}^{n} x_{i}\right)}, \\
& b_{1}=\frac{n \cdot \sum_{i=1}^{n} x_{i} U_{c i}^{\ni}-\sum_{i=1}^{n} x_{i} \cdot \sum_{i=1}^{n} U_{c i}^{\ni}}{n \cdot \sum_{i=1}^{n} x_{i}^{2}-\left(\sum_{i=1}^{n} x_{i}\right)} .
\end{aligned}
$$


For estimating the linear force, the sample correlation coefficient is calculated (formula 9):

$$
r=\frac{\sum_{i=1}^{n}\left(x_{i}-\bar{x}\right)^{2} \cdot\left(U_{c i}^{\ni}-\bar{U}\right)}{\sqrt{\sum_{i=1}^{n}\left(x_{i}-\bar{x}\right)^{2} \cdot\left(U_{c i}^{\ni}-\bar{U}\right)^{2}}} .
$$

Depending on the correlation coefficient, the following conclusions are usually made:

$0 \prec|r| \prec 0,2$ - between the forecast value of demand and the factor that determines it, there is no relationship; $0,2 \prec|r| \prec 0,5$ - tenuous relationship; $0,5 \prec|r| \prec 0,75$ average relationship; $0,75 \prec|r| \prec 0,95 \quad$ - strong relationship; $0,95 \prec|r| \prec 1$ - functional relationship.

For prestigious services, such as the sale of seats in elevated carriages, a significant increase in prices affects insignificantly the volume of demand; however, if prices rise quite high, demand levels will be lower than $U_{c 1}$, as a result of the curvature curve to the side. In this case, passengers will buy tickets to other types of cars, comparing the price and quality of the services offered, or use of the services of other modes of transport.

The resulting amount of demand for transport services, in this case, is formed under the influence of not one, but several key factors. To study their effect on demand, we consider it expedient to use the method of multiple regression, which reflects the statistical relationship of the value of the service with a group of other factors, on which it depends. In general, this dependence is described by the equation 10:

$$
U_{c}=\int\left(x_{1}, x_{2}, x_{3}, \ldots, x_{n}\right),
$$

Where: $x_{1}, x_{2}, x_{3}, \ldots, x_{n}$ - the factors on which the forecast value of demand depends.

In most practical calculations, models are used to establish multivariate dependencies:

- linear (multifactorial):

$$
U_{c}=a+\sum_{i=1}^{n} b_{i} x_{i}
$$

- degree $U_{c}=x_{1}^{b_{1}} \cdot x_{2}^{b_{2}} \cdot x_{3}^{b_{3}} \cdot \ldots x_{n}^{b_{n}}$;

- non-linear:

$$
\begin{aligned}
& U_{c}=a+b_{1} x_{1}+b_{2} x_{2}+\ldots+b_{n} x_{n}+b_{11} x_{1}^{2}+b_{12} x_{1} x_{2}+\ldots \\
& +b_{1 n} x_{1} x_{n}+b_{22} x_{2}^{2}+b_{23} x_{2} x_{3}+\ldots+b_{2 n} x_{2} x_{n}+\ldots+ \\
& +b_{n-1, n-1} x_{n-1}^{2}+b_{n-1, n} x_{n-1} x_{n}+\ldots+b_{n} x_{n}^{2},
\end{aligned}
$$

Where: $b_{i}$ - beta coefficients; $a$ - bias; $x_{i}$ - a factor that creates the demand.

Dependence of demand and price, in this case, is determined by the mathematical methods.

The establishment of interconnections between transport services and demand allows the passenger to assess the effectiveness of the relevant set of services, provide break-even work, and establish a sustainable strategy for operation in the transport market.

The choice of a passenger car category depends on its cultural level, the cost of tickets for wages $C_{i}$, purchasing power $y_{\Pi C}^{1}$ at time $\mathrm{t}$ and other factors.
Passengers with low wages and low purchasing power, basically, buy tickets for seats in the couchette cars and general wagons, and with high $y_{\Pi C}^{1}$ - in seats in the compartments and cars "SC". In the general case, each passenger with a specified $Y_{\Pi C}^{1}$ one may, with a certain probability $\left(P_{\mathrm{i}}^{\mathrm{x}}, P_{i}^{y}, P_{i}^{z}, P_{i}^{k}\right)$ can buy tickets for seats in the cars "SC" $(x)$, compartment $(y)$, couchette car $(z)$, and general $(k)$ wagons. All predicted passenger flow Ac on a specific destination of a train can be divided into passengers who want to go in the car "SC" $\left(A_{c}^{x}\right)$, compartment $\left(A_{c}^{y}\right)$, economy class $\left(A_{c}^{z}\right)$, and general $\left(A_{c}^{k}\right)$ types of trains, that is:

$$
A_{c}^{k}=\left(A_{c}^{x}+A_{c}^{y}+A_{c}^{z}+A_{c}^{k}\right) .
$$

Given the probability of passenger demand for seats in cars of different categories of trains, the values of the corresponding clauses can be represented as follows:

$$
\begin{aligned}
& A_{c}^{x}=P_{1}^{x}\left(y_{\Pi C 1}^{t}\right) \cdot A_{c 1}\left(y_{\Pi C 1}^{t}\right)+P_{2}^{x}\left(y_{\Pi C 2}^{t}\right) \cdot A_{c 2}\left(y_{\Pi C 2}^{t}\right)+\ldots \\
& \ldots+P_{m}^{x}\left(Y_{\Pi C M}^{t}\right) \cdot A_{c m}\left(Y_{\Pi C M}^{t}\right), \\
& A_{c}^{y}=P_{1}^{y}\left(y_{\Pi C 1}^{t}\right) \cdot A_{c 1}\left(Y_{\Pi C 1}^{t}\right)+P_{2}^{y}\left(y_{\Pi C 2}^{t}\right) \cdot A_{c 2}\left(y_{\Pi C C 2}^{t}\right)+\ldots \\
& \ldots+P_{m}^{y}\left(Y_{\Pi C M}^{t}\right) \cdot A_{c m}\left(Y_{\Pi C M}^{t}\right), \\
& A_{c}^{k}=P_{1}^{k}\left(y_{\Pi C 1}^{t}\right) \cdot A_{c 1}\left(y_{\Pi C 1}^{t}\right)+P_{2}^{k}\left(y_{\Pi C 2}^{t}\right) \cdot A_{c 2}\left(y_{\Pi C 2}^{t}\right)+\ldots \\
& \ldots+P_{m}^{k}\left(Y_{\Pi C M}^{t}\right) \cdot A_{c m}\left(Y_{\Pi C M}^{t}\right) \text {, }
\end{aligned}
$$

where: $P_{1}^{x}\left(y_{\Pi C 1}^{t}\right), P_{1}^{y}\left(y_{\Pi C 1}^{t}\right), \ldots, P_{1}^{k}\left(y_{\Pi C 1}^{t}\right)$ - the probability of passenger demand for seats in cars of the corresponding category with purchasing power $\boldsymbol{Y}_{\Pi C 1}^{t}$ at time $t$

$A_{1}^{x}\left(y_{\Pi C 1}^{t}\right)$ - a total number of passengers with purchasing power $\boldsymbol{Y}_{\Pi C 1}^{t}$ at the time $t$.

Moreover, the following condition must be observed (formula 15):

$$
\begin{aligned}
& A_{c}=\sum A_{c i}^{t}\left(y_{\Pi C 1}^{t}\right), \\
& P_{i}^{x}\left(y_{\Pi C i}^{t}\right)+P_{i}^{y}\left(y_{\Pi C i}^{t}\right)+\ldots+P_{i}^{k}\left(y_{\Pi C i}^{t}\right)=1 .
\end{aligned}
$$

With a sufficient number of passenger wagons of each category in the passenger railroad reserve, to ensure the demand of passengers for the intended pattern of formation of a train, it is possible to determine (Kyrylenko, 2014; Razumova, 2014):

$$
\begin{aligned}
& x=A_{c}^{x}=\frac{P_{1}^{x}\left(y_{\Pi C 1}^{t}\right) \cdot A_{c 1}\left(y_{\Pi C 1}^{t}\right)+P_{2}^{x}\left(y_{\Pi C 2}^{t}\right) \cdot A_{c 2}\left(y_{\Pi C 2}^{t}\right)+\ldots+P_{m}^{x}\left(y_{\Pi C M}^{t}\right) \cdot A_{c n}\left(y_{\Pi C M}^{t}\right)}{\beta_{x}^{\min } a_{x}}, \\
& y=A_{c}^{y}=\frac{P_{1}^{y}\left(y_{\Pi C 1}^{t}\right) \cdot A_{c 1}\left(y_{\Pi C 1}^{t}\right)+P_{2}^{y}\left(y_{\Pi C 2}^{t}\right) \cdot A_{c 2}\left(y_{\Pi C 2}^{t}\right)+\ldots+P_{m}^{y}\left(y_{\Pi C M}^{t}\right) \cdot A_{c n}\left(y_{\Pi C M}^{t}\right)}{\beta_{y}^{\min } a_{y}},(16) \\
& k=A_{c}^{k}=\frac{P_{1}^{k}\left(y_{\Pi C 1}^{t}\right) \cdot A_{c 1}\left(y_{\Pi C 1}^{t}\right)+P_{2}^{k}\left(y_{\Pi C 2}^{t}\right) \cdot A_{c 2}\left(y_{\Pi C 2}^{t}\right)+\ldots+P_{m}^{k}\left(y_{\Pi C M}^{t}\right) \cdot A_{c n}\left(y_{\Pi C M}^{t}\right)}{\beta_{k}^{\min } a_{k}} .
\end{aligned}
$$

Where: $a_{x}, a_{y}, \ldots, a_{k}$ - replacement of the car of the relevant category;

$\beta_{x}^{\min } a_{x}, \beta_{y}^{\min } a_{y}, \beta_{k}^{\min } a_{k}$ - the minimum permissible level of population, respectively, compartment, economy class, and general types of cars, in which the passenger service is advantageous to include them in the composition of the train on a given destination. 
Each train is limited to the length of passenger platforms at start-stop and intermediate stations where there is a stop. Typically, this restriction is set by the number of cars included in the train:

$$
x+y+\ldots+k \leq m_{c} .
$$

Lowering the purchasing power level of the time period $t+\Delta t$ due to the increasing consumer prices without raising wages, consumers' demand for transport services is changing $A_{c i}\left(y_{\Pi C i}^{t}\right)$ on the value $a_{O T i}^{t+\Delta t}\left(y_{\Pi C i}^{t+\Delta t}\right)$ :

$$
A_{c i}^{t+\Delta t}\left(y_{\Pi C i i}^{t+\Delta t}\right)=A_{c i}^{t}\left(Y_{\Pi C i}^{t}\right) \cdot\left(1-a_{O T i}^{t+\Delta t}\left(y_{\Pi C i}^{t+\Delta t}\right)\right),
$$

where: $a_{O T i}^{t+\Delta t}\left(y_{\Pi C i}^{t+\Delta t}\right)$ - the probability of refusal to travel passengers with purchasing power $y_{\Pi C 1}$ at the time $t+\Delta t$.

For the development of the growing passenger traffic, the railways try to increase the capacity of trains by including in the scheme of formation of the most capacious types of cars, which leads to a decrease in the quality of passenger service, and sometimes - the population of trains.

An analysis of results of the study of passenger traffic in some areas of the rail network showed that the replacement of the required type of carriages by others leads to the refusal of a certain number of passengers from the trip. Obviously, the change in the schemes of formation of passenger trains, without considering the demand of the population for places by types of cars, can lead to serious losses of profits of passenger railways and an increase in dissatisfaction with the demand of passengers. Considering the need of passengers and the requirements of rail transport, the task of choosing rational schemes for the formation of passenger trains can be formulated in the following form.

From the car park, which is available, to determine such a scheme for the formation of passenger trains, which would ensure the transportation of the planned number of passengers, would as much as possible satisfy the demand of the population for places by types of cars and was profitable for rail transport.

Let's represent the problem in mathematical form. For each specific attraction, the satisfaction of the demand of the population to the place may occur at the expense of free places and other types of cars, that is, if the demand for one of the types of cars dissatisfies, some of the passengers buy tickets for vacancies in other types, and part refuses to travel in general. Mathematically, this can be represented as a system of equations 19 (Razumova, 2014):

$$
\left\{\begin{array}{l}
A_{c}^{x} \leq a_{x} x+\left(1-a_{y}^{x}\right) a_{y} y+\left(1-a_{z}^{x}\right) a_{z} z+\left(1-a_{k}^{x}\right) a_{k} k ; \\
A_{c}^{y} \leq a_{y} y+\left(1-a_{x}^{y}\right) a_{x} x+\left(1-a_{z}^{y}\right) a_{z} z+\left(1-a_{k}^{y}\right) a_{k} k ; \\
A_{c}^{z} \leq a_{x} x+\left(1-a_{x}^{z}\right) a_{x} x+\left(1-a_{y}^{z}\right) a_{y} y+\left(1-a_{k}^{z}\right) a_{k} k ; \\
A_{c}^{k} \leq a_{k} k+\left(1-a_{x}^{k}\right) a_{x} x+\left(1-a_{y}^{k}\right) a_{y} y+\left(1-a_{z}^{k}\right) a_{z} z,
\end{array}\right.
$$

where: $A_{c}^{x}, A_{c}^{y}, A_{c}^{z}, A_{c}^{k}$ - population demand for seats, respectively, in "SC", compartment, couchette car, and general wagons; $x, y, z, k$ - unknown value, respectively, of soft, compartment, economy class, and common rail cars;

$a_{x}^{y}, a_{z}^{y}, a_{k}^{y}$ - the probability of a passenger's refusal from a trip in case of dissatisfaction with the demand for a place in a compartment carriage and the presentation of a place in the carriages of "SC", on the economy class, and on the general carriages;

$a_{x}^{z}, a_{z}^{z}, a_{k}^{z}$ - the probability of a passenger's refusal from a trip in case of dissatisfaction with the demand for a place in the placard carriage and the presentation of the place in the carriages of "SC", compartment, and general wagons;

$a_{x}^{k}, a_{z}^{k}, a_{k}^{k}$ - the probability of a passenger's refusal from a trip if dissatisfied with the demand for a place in the general carriage and the presentation of the place, respectively, in the "SC" cars, compartment, and general wagons.

When choosing schemes for the formation of passenger trains to provide transportation of the population of the planned passenger flow, an opportunity to make a trip, expressed in the ratio (formula 20), should be presented:

$$
A_{n} \leq a_{x} x+a_{y} y+a_{z} z+a_{k} k
$$

For a passenger economy, it is necessary to ensure the profitability of passenger transportation. This condition for each type of train included in the train can be written in the following form (Razumova, 2014):

$$
\left\{\begin{array}{l}
A_{c}^{x}-\left(1-a_{x}^{y}\right) a_{y} y-\left(1-a_{z}^{x}\right) a_{z} z-\left(1-a_{k}^{x}\right) a_{k} k+ \\
+A_{c}^{y}-a_{y} y-\left(1-a_{z}^{y}\right) a_{z} z-\left(1-a_{k}^{y}\right) a_{k} k+ \\
+A_{c}^{z}-a_{z} z-\left(1-a_{y}^{z}\right) a_{x} y-\left(1-a_{k}^{z}\right) a_{k} k+ \\
+A_{c}^{k}-a_{k} k-\left(1-a_{y}^{k}\right) a_{y} y-\left(1-a_{z}^{k}\right) a_{z} z \geq \beta_{x}^{\min } a_{x} x, \\
A_{c}^{x}-a_{x} x-\left(1-a_{z}^{x}\right) a_{z} z-\left(1-a_{k}^{x}\right) a_{k} k+ \\
+A_{c}^{y}-\left(1-a_{x}^{y}\right) a_{x} x-\left(1-a_{z}^{y}\right) a_{z} z-\left(1-a_{k}^{y}\right) a_{k} k+ \\
+A_{c}^{z}-a_{z} z-\left(1-a_{x}^{z}\right) a_{x} x-\left(1-a_{k}^{z}\right) a_{k} k+ \\
+A_{c}^{k}-a_{k} k-\left(1-a_{x}^{k}\right) a_{x} x-\left(1-a_{z}^{k}\right) a_{z} z \geq \beta_{y}^{\min } a_{y} y, \\
A_{c}^{x}-a_{x} x-\left(1-a_{y}^{x}\right) a_{y} y-\left(1-a_{k}^{x}\right) a_{k} k+ \\
+A_{c}^{y}-a_{y} y-\left(1-a_{x}^{y}\right) a_{x} x-\left(1-a_{k}^{y}\right) a_{k} k+ \\
+A_{c}^{z}-\left(1-a_{x}^{z}\right) a_{x} x-\left(1-a_{y}^{z}\right) a_{y} y-\left(1-a_{k}^{z}\right) a_{k} k+ \\
+A_{c}^{k}-a_{k} k-\left(1-a_{x}^{k}\right) a_{x} x-\left(1-a_{y}^{k}\right) a_{y} y \geq \beta_{z}^{\min } a_{z} z, \\
A_{c}^{x}-a_{x} x-\left(1-a_{y}^{x}\right) a_{y} y-\left(1-a_{z}^{x}\right) a_{z} z+ \\
+A_{c}^{y}-a_{y} y-\left(1-a_{x}^{y}\right) a_{x} x-\left(1-a_{z}^{y}\right) a_{z} z+ \\
+A_{c}^{z}-a_{z} z-\left(1-a_{x}^{z}\right) a_{x} x-\left(1-a_{y}^{z}\right) a_{y} y-\left(1-a_{k}^{z}\right) a_{k} k+ \\
+A_{c}^{k}-\left(1-a_{x}^{k}\right) a_{x} x-\left(1-a_{y}^{k}\right) a_{y} y-\left(1-a_{z}^{k}\right) a_{z} z \geq \beta_{k}^{\min } a_{k} k .
\end{array}\right.
$$

However, the number of cars of each type should not exceed the existing reserve of passenger cars, i.e.:

$$
\begin{aligned}
& T_{o \sigma} x " B_{x}, \\
& T_{o \sigma} y " B_{y}, \\
& T_{o \sigma} z " B_{z}, \\
& T_{o \sigma} k " B_{k},
\end{aligned}
$$

where: $B_{x}, B_{y}, B_{z}, B_{k}$ - the existing park in accordance with "SC" carriages, compartment, couchette car, and general passenger cars; 
$T_{o 6}$ - the time of traction on a given route.

A rational scheme for the formation of a passenger train composition will be that which ensures the minimum number of refusals of passengers from the trip. That is, to solve the problem, it is necessary to minimize the function (formula 23) using the complex method of linear programming, on the constraints in the systems of equations 21 and 22 :

$$
\begin{aligned}
& F=a_{y}^{x} a_{y} y+a_{z}^{x} a_{z} z+a_{k}^{x} a_{k} k+a_{x}^{y} a_{x} x+a_{z}^{y} a_{z} z+a_{k}^{y} a_{k} k+a_{x}^{z} a_{x} x+ \\
& +a_{y}^{z} a_{y} y+a_{k}^{z} a_{k} k+a_{x}^{k} a_{x} x+a_{y}^{k} a_{y} y+a_{z}^{k} a_{z} z \rightarrow \min .
\end{aligned}
$$

Calculations of the schemes for the formation of passenger trains made according to this method allow improving the quality of passenger traffic and the efficiency of the use of the car park.

\section{Catering costs}

A special place in the service of passengers during the trip is catering. The organization of catering for passengers in trains is one of the most profitable accompanying services and the biological necessity of a person. In the railway transport, a comprehensive system for providing and organizing the feeding of passengers in trains should be developed, based on modern and advanced technologies that provide for certain dietary standards, depending on the duration of the trip and the timetable of trains, and take into account the specifics of the consumption of food for a particular category of passengers.

Finding passengers on the way up to 3 hours already needs to provide him, at least, drinks to choose from: juice, water of different kinds, tea, coffee, milk and, if desired, yogurt or ice cream. With a trip duration of 3 to 5 hours, it is advisable for passengers, along with drinks, to offer light meals: cold snacks, sandwiches, pastries and other products and confectionery products formed in "lunchboxes". For a longer trip, passengers need hot meals. It is also impossible to disregard the inhomogeneity of passenger traffic in rail transport by nationalities, religious beliefs, ethnic groups, and physical health. The passenger should always have the choice of the offered dishes.

Let there be a set of products (meat, fish, milk, butter, cheese, cereals, bread, etc.) at a price $C_{1}, C_{2}, \ldots, C_{j}, \ldots, C_{n}$. respectively. Moreover, the stocks of these products are limited in terms of delivery, preservation: $a_{1}, a_{2}, \ldots, a_{j}, \ldots, a_{n}$.

The content of the nutrients (proteins, fats, carbohydrates, mineral salts) in $100 \mathrm{~g}$ of each product are known and are respectively: $\rho_{i j}(i=1,2,3 \ldots ; j=1,2,3 \ldots$.$) .$ In addition, the norms of daily human need in every nutrient are known: $b_{1}, b_{2}, \ldots, b_{j}, \ldots, b_{n}$.
It is necessary to determine the number of sets of procured products $x_{1}, x_{2}, \ldots, x_{j}, \ldots, x_{n}$, which will provide the need for nutrients of each species and will have a minimal cost.

Since the nutrient content in the diet should be at least $b_{1}, \ldots, b_{m}$, we obtain a system of linear restrictions (24):

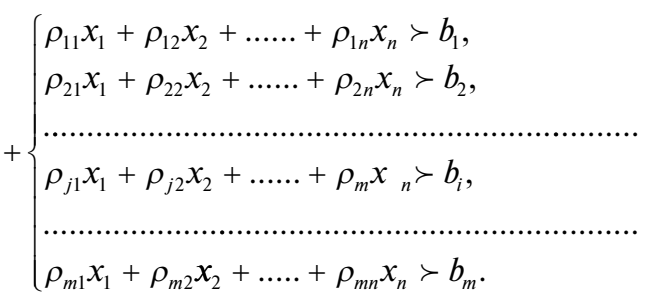

In addition, the quantity of each product in the diet of each passenger cannot be negative, and the size of procurement is limited to stocks:

$$
0 \prec x_{1} \prec a_{1}, 0 \prec x_{2} \prec a_{2}, \ldots, 0 \prec x_{j} \prec a_{j}, \ldots, 0 \prec x_{n} \prec a_{n} .
$$

The total value of the diet will be recorded as a linear target function:

$$
F(x)=C_{1} \cdot x_{1}+C_{2} \cdot x_{2}+\ldots+C_{n} \cdot x_{n} .
$$

Thus, solving the problem of linear programming in known ways, you can get a balanced daily diet of a passenger.

\section{Conclusions}

So, it was proved that passengers on the way up to 3 hours already need to be provided at least with drinks to choose from: juice, water of different kinds, tea, coffee, milk, and others. With a trip duration of 3 to 5 hours, passengers, along with drinks, should be offered with light meals: cold snacks, sandwiches, sandwiches, pastries and other products and confectionery products formed in "lunch boxes". For a longer trip, passengers need hot meals.

The article proposes the model of service development for passengers, which is based on the development of the model of the total cost of the passenger's diet and allows them to meet their nutritional needs with minimal costs. The task of rational nutrition is solved in the conditions of a limited range of commodity stocks, costs, daily human consumption standards of consumer substances and their content in products and beverages. In any case, from all possible options, you need to choose the most economical ones.

Also, this model is based on modern and advanced technologies, which provides for certain dietary standards, depending on the trip duration and schedule of trains, and takes into account the specifics of the consumption of food for a particular category of passengers. 
Vol. 4, No. 2, 2018

\section{References:}

Shchelkunov V., Kyrylenko O. and oth. (2011) Osnovy ekonomiki transportu. [Basis of transport economics]. Kyiv: Condor. (in Ukrainian)

Novak V., Makarenko L., Lutskyy M. (2006) Informatsiyne zabezpechennya menedzhmentu. [Information support of management]. Kyiv: Kondor. (in Ukrainian)

Aksonov I.M., Haba V.V., Sherepa K.M. (2012) Transportna logistyka [Transport logistics: a tutorial]. Kiev: DETUT. in Ukrainian)

Kyrylenko O.N. (2014) Ekonomicheskaya effektivnost metoda ekspluatatsii nizkoskorostnykh liniy. [The economic efficiency of the method of operation of low-traffic lines]. Economy of Railways. Moskow, Vol. 8, pp. 79-85.

Razumova K.N. (2014) Ocinka konkurentnykh pozycij pidpryyemstv pasazhyrskogo transportu z urakhuvannyam loyalnosti strategichnykh partneriv [Assessment of competitive positions of the enterprises of passenger transport, taking into account loyalty strategic partners]. Problems of system approach in Economics, Vol. 50, pp. 79-82. 